\title{
Penerapan Data Mining Korelasi Penjualan Spare Part Mobil Menggunakan Metode Algoritma Apriori (Studi Kasus: CV. Citra Kencana Mobil)
}

\author{
Amenta Ovilianda Br Ginting 1) \\ 1) Program Studi Sistem Informasi, STIK KAPUTAMA Binjai \\ Jl. Veteran No. 4A-9A, Binjai 20714, Sumatera Utara
}

Riwayat : Copyright (C2021, JTU, Submitted: 20 Maret 2021; Revised: 22 Juli 2021; Accepted: 06 Agustus 2021; Published: 01 September 2021

\begin{abstract}
By utilizing customer data that has been stored in the database, the management can find out how the current sales system is less efficient, therefore a system is needed to process information data more quickly and accurately in increasing sales of car spare parts using the Data Mining application. The Apriori Algorithm method that works by searching for and finding associated patterns among the products being marketed, so that later it can help companies improve the associated items. And with the sales transaction data, the company can know better how they should increase the spare part stock in the company. From the results of testing the sale of car spare parts with 589 data, it was found that 81 rules were formed and the highest Best Rule was obtained and a minimum support value of $1 \%$ and a confidence value of $11 \%$ If the type of car is Avanza / Xenia and the brand is Toyota, the spare parts used are filters. Air. With supporting spare parts in the database of $1 \%$ and certainty of spare parts of 11.
\end{abstract}

Keywords - Data Mining, Apriori Algorithm, Sales of Spare Parts

Abstrak - Dengan memanfaatkan data pelanggan yang telah tersimpan dalam database, maka pihak manajemen dapat mengetahui bagaimana sistem penjualan yang berjalan saat ini kurang efisien, maka dari itu diperlukanya suatu siste muntuk mengolah data informasi lebih cepat dan tepat dalam meningkatkan penjualan Spare Partmobil dengan menggunakan aplikasi Data Mining metode Algoritma Apriori yang bekerja dengan cara mencari dan menemukan pola-pola yang berasosiasi diantara produk-produk yang dipasarkan, agar nantinyadapat membantu perusahaan dalam meningkatkan lagi itemitem barang yang berasosiasi tersebut. Dan dengan adanya data transaksi penjualan maka perusahaan dapat mengetahui dengan lebih baik bagaimana mereka harus meningkatkan stok spare part diperusahaan. Dari hasil pengujian penjualan

\footnotetext{
*) Penulis korespondensi (Amenta Ovilianda)
} Email: gintingmentaovilianda81@gmail.com sparepart mobil dengan jumlah data 589 data, ditemukan 81 rule yang terbentuk dan diperoleh Best Rule tertinggi dan nilai minimum support $1 \%$ dannilai confidence $11 \%$ Jika jenis Mobil adalah Avanza / Xenia dan Merka dalah Toyota maka sparepart yang digunakan adalah Filter Udara. Dengan sparepart pendukung di dalam database sebesar $1 \%$ dan sparepart kepastian sebesar 11\%.

Kata kunci - MOORA; Pemilihan Sarana dan Prasarana; Sistem Pendukung Keputusan

\section{Pendahuluan}

\section{A. Latar Belakang Masalah}

Dengan adanya perkembangan teknologi yang semakin canggih dan mudah digunakan sehinggamemotivasi kita untuk mengetahui arti pentingnya akan kegunaan komputer dalam proses pengolahan data yang cepat dan praktis.Akan tetapi di zaman yang berkembang seperti saat ini mengakibatkan dunia usaha semakin kompleks dan kompetitif dalam persaingannya dengan banyaknya perusahaan industri, jasa maupun perusahaan yang bergerak di bidang yang samajuga harus bersaing ketat dalam meraih pembeli yang ada.

Dengan memanfaatkan data pelanggan yang telah tersimpan dalam database, maka pihak manajemen dapat mengetahui bagaimana sistem penjualan yang berjalan saat ini kurang efisien, maka dari itu diperlukanya suatu sistem untuk mengolah data informasi lebih cepat dan tepat dalam meningkatkan penjualan Spare Part mobildengan menggunakan aplikasi Data Mining metode Algoritma Apriori yang bekerja dengan cara mencari dan menemukan pola-pola yang berasosiasi diantara produkproduk yang dipasarkan, agar nantinya dapat membantu perusahaan dalam meningkatkan lagi item-item barang yang berasosiasi tersebut. Dan dengan adanya data transaksi penjualan maka perusahaandapat mengetahui dengan lebih baik bagaimana mereka harus meningkatkan stok spare partdi perusahaan.

CV. Citra Kencana Mobil merupakan perusahaan yang bergerak di bidang jasa otomotif yang melayani 
pembelian, penjualan sparepart mobil dan pelayanan jasa service.Perusahaan ini juga membuat berbagai laporan transaksi, seperti laporan pembelian spare part mobil, laporan penjualan sparepart mobil.Selain itu perusahaan juga mengelola berbagai data stok spare part baik spare part yang masuk dari distributor maupun sparepart yang keluar untuk di jual kembali pada pelanggan.[1][2]

Penelitian ini diperkuat oleh Jurnal Sistem Informasi, Universitas Potensi Utama, Vol.8 No.3, Oktober 2015 yang dilakukan oleh penulis Khairul Ummi dengan judul "Analisa Data Mining Dalam Penjualan Spare Part Mobil Dengan Menggunakan Metode Algoritma Apriori(Studi Kasus : Di Pt. Idk 1 Medan)”. yang bertujuan untuk mendapatkan informasi tentang asosiasi antar produk dari suatu database transaksi. Data transaksi penjualan suku cadang mobil honda di PT. IDK 1 dapat diolah kembali menggunakan aplikasi Data Mining sehingga menghasilkan aturan asosiasi keterkaitan yang kuat antar itemset penjualan suku cadang sehingga bisa memberi rekomendasi penyetokan barang dan mempermudah dalam penataan atau penempatan barang yang kuat berkaitan saling ketergantungan.[3][4]

Dan diperkuat oleh Sepri, D., Afdal, M., \& Riau, S. (2017). Analisa Dan Perbandingan Metode Algoritma Apriori Dan Fp-Growth Untuk Mencari Pola Daerah Strategis Pengenalan Kampus Studi Kasus Di Stkip Adzkia Padang. Jurnal Sistem Informasi Kaputama (JSIK). Yang bertujuan untuk dimanfaatkan oleh dalam menentukan daerah yang strategis. Dalam penelitian ini penulis mencoba membandingkan hasil dari algoritma Apriori dan FP-Growth yang menggunakan data mahasiswa angkatan 2015/2016 dengan nilai minsupport $=0.05 \%$ dan nilai minconfidence $=0.7 \%$ telah diperoleh 19 Association Rule dan 2 rule tertinggi yang dapat dijadikan sebagai pengetahuan baru serta acuan berharga pada lingkup penelitian ini.[5][6]

\section{B. Rumusan Masalah}

Dari uraian diatas, maka yang menjadi rumusan masalah dalam penelitian ini adalah sebagai berikut:

1. Bagaimana cara membangun sebuah aplikasi data mining berdasarkan data korelasi penjualan spare part mobil dengan menggunakan WEKA?

2. Bagaimana menggunakan Algoritma Apriori kedalam sistem data mining untuk menghasilkan informasi yang terbaru dengan aplikasi WEKA?

3. Bagaimana aplikasi pengolahan data ini dapat membantu pihak perusahaan mengambil keputusan dan menyusun strategi promosi yang lebih cepat dalam penjualan spare part mobil?

\section{Batasan Masalah}

Adapun batasan masalah yang akan dibahas oleh penulis adalah sebagai berikut;

1. Data yang digunakan yaitu data penjualan mobil dari tahun 2014 sampai 2019.
2. Metode yang digunakan yaitu Algoritma Apriori serta menggunakan WEKA sebagai penentu rule, bahasa pemrograman PHP dan database.

3. Variabel yang digunakan yaitu jenis kendaraan, jenisspare partdan Merk Kendaraan.

\section{Tujuan Penelitian}

Adapun tujuan penelitian yang akan dicapai dalam penyusunan skripsi ini adalah sebagai berikut:

1. Untukmembangun sebuah aplikasi data mining berdasarkan data korelasi penjualan spare part mobil dengan menggunakan WEKA.

2. Untuk membuat aplikasi program yang dapat membantu penyajian informasi yang dibutuhkan untuk pendukung keputusan Citra Kencana Mobil dengan data-data penjualan spare part mobil.

3. Dengan adanya sebuah aplikasi pengolahan data ini berguna untuk membantu pihak perusahaan mengambil keputusan dan menyusun strategi promosi yang lebih cepat dalam penjualan spare part mobil.

\section{E. Manfaat Penelitian}

Adapun manfaat yang didapat dari penyusunan skripsi ini adalah:

1. Membantu perusahaan dalam memberikan informasi yang jelas dan cepat terhadap perusahan dalam menentukan strategi promosi penjualan spare part mobil untuk meningkatkan penjualan tersebut.

2. Untuk mengetahui tingkat penjualan yang sedang berjalan saat ini dan meningkatkan stok spare part yang dibutuhkan pelanggan.

3. Untuk membantu pihak perusahaan mengambil keputusan dalam penjualan spare part mobil menggunakan metode Apriori.

\section{LANDASAN TEORI}

\section{A. Penelitian Terdahulu}

Jurnal Sistem Informasi, Universitas Potensi Utama, Vol.8 No.3, Oktober 2015 yang dilakukan oleh penulis Khairul Ummi dengan judul "Analisa Data Mining Dalam Penjualan Spare Part Mobil Dengan Menggunakan Metode Algoritma Apriori(Studi Kasus: Di Pt. Idk 1 Medan)", yang bertujuan untuk mendapatkan informasi tentang asosiasi antar produk dari suatu database transaksi. Data transaksi penjualan suku cadang mobil honda di PT. IDK 1 dapat diolah kembali menggunakan aplikasi Data Mining sehingga menghasilkan aturan asosiasi keterkaitan yang kuat antar itemset penjualan suku cadang sehingga bisa memberi rekomendasi penyetokan barang dan mempermudah dalam penataan atau penempatan barang yang kuat berkaitan saling ketergantungan.[7][8] 


\section{B. Data Mining}

Data mining merupakan gabungan dari beberapa displin ilmu yang menyatukan teknik dari pembelajaran mesin, pengenalan pola, statistic, database, dan visualisasi untuk penanganan permasalahan pengambilan informasi dari database yang besar.[9]

\section{Pengertian Knowledge Discovery in Databases (KDD)}

Knowledge Discovery in Database (KDD) merupakan metode untuk memperoleh pengetahuan dari database yang ada.Dalam database terdapat tabel - tabel yang saling berhubungan / berelasi. Hasil pengetahuan yang diperoleh dalam proses tersebut dapat digunakan sebagai basis pengetahuan (knowledge base) untuk keperluan pengambilan keputusan.

Proses KDD dapat digambarkan sebagai berikut:

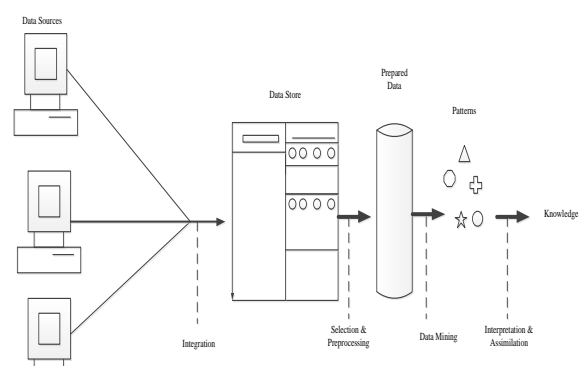

Gambar 1. Proses Knowledge Discovery in Database (KDD)

\section{Pengertian Apriori}

Algoritma apriori adalah suatu algoritma dasar yang diusulkan oleh Agrawal \& Skrikant pada tahun 1994 untuk menentukan frequent itemsets untuk aturan asosiasi Boolean. Algoritma Apriori termasuk jenis aturan asosiasi pada data mining.Aturan yang menyatakan asosiasi antara beberapa atribut sering disebut affinity analysis atau market basket analysis.

\section{E. Definisi Penjualan}

Penjualan adalah sebuah usaha atau langkah konkrit yang dilakukan untuk memindahkan suatu produk, baik itu berupa barang atau jasa, dari produsen kepada konsumen sebagai sasarannya.Tujuan utama penjualan yaitu mendatangkan keuntungan atau laba dari produk atau barang yang dihasilkan produsennya dengan pengelolaan yang baik.

\section{F. Definisi Suku Cadang / Spare Part}

Suku cadang /Spare Part adalah suatu barang yang terdiri dari beberapa komponen yang membentuk satu kesatuan dan mempunyai fungsi tertentu. Setiap alat berat terdiri dari banyak komponen, namun yang akan dibahas komponen yang sering mengalami kerusakan dan penggantian. Ada beberapa komponen yang juga terdapat didalamnya beberapa komponen kecil, misalkan enginee yang mempunyai komponen didalamnya, yaitu fuel injection pump, water pump, starting motor, alternator, oil pump, compressor, power steering pump, turbocharger, dan lain-lain.

\section{G. Database}

Menurut Mukhlisulfatih Latief (2010; h.231), "Database merupakan kumpulan dari item data yang saling berbuhubungan satu dengan yang lainnya yang diorganisasikan berdasarkan sebuah skema atau struktur tertentu, tersimpan dihardware computer dan dengan software untuk melakukan manipulasi untuk kegunaan tertentu".

\section{H. Pengertian WEKA}

WEKA adalah sebuah paket tools machine learning praktis. WEKA merupakan singkatan dari "Waikato Environment for Knowladge Analysis", yang dibuat di Universitas Waikato, New Zaeland untuk penelitian, pendidikan dan berbagai aplikasi. WEKA mampu menyelesaikan masalah-masalah data mining di dunia nyata, khususnya klasifikasi yang mendasari pendekatan machine learning. Perangkat lunak ini ditulis dalam hirarki class java dengan metode beriorentasi objek dan dapat berjalan hampir disemua platform.

\section{PHP (Personal Home Page / Form Interface)}

PHP / Fi merupakan nama awal dari PHP (Personal Home Page / Form Interface). Dibuat pertama kali oleh Rasmus Lerdoff. PHP awalnya merupakan Program CGI yang dikhususkan untuk menerima input melalui form yang ditampilkan dalam browser web.

\section{ANALIS DAN PERANCANGaN}

\section{A. Analisa Rancangan}

Dalam proses penelitian ini, ditunjukan untuk lebih memberikan hasil yang berarti bagi pihak dalam menangani penjualan spare part mobil agar tidak terjadi kesalahan dalam melayani pelanggan.

Hasil dari konseptualisasi akan dituangkan menjadi satu metode penelitian yang lekat dengan pola studi literature, pengumpulan data yang diperlukan untuk menganalisis system dengan menggunakan algoritma Apriori.

- Persiapan

Tahap ini merupakan kegiatan awal yaitu dengan penentuan penelitian dari latar belakang masalah kemudian dilakukan batasan masalah selanjutnya dilakukan penentuan tujuan serta manfaat yang dilakukan dalam penyusunan proses data mining.

- Kajian Teori

Pada tahap ini dilakukan kajian teori terhadap masalah yang ada. Kajian yang dilakukan untuk menentukan konsep yang akan digunakan dalam penelitian.

- $\quad$ Pengumpulan Data 
Tahap ini pengumpulan data-data pendukung yang dibutuhkan dalam proses perancangan data mining ini. Data-data tersebut dapat diperoleh dari hasil penelitian, buku-buku, jurnal-jurnal serta informasi dari internet.

Analisa Data

Tahap ini akan dilakukan analisa data-data pendukung yang telah diperoleh pada tahapan sebelumnya.

Pengujian dan Implementasi Sistem

Tahap ini melakukan pengujian validasi dan implementasi data yang telah di analisa sebelumnya serta penyusunan program.

Tahap Akhir

Pada tahap akhir ini perancangan data mining akan dibahas kesimpulan dan saran yang diperlukan untuk pengembangan program selanjutnya.

\section{B. Flowchart Algoritma}

Adapun rancangan flowchart dapa software WEKA dapat digambarkan sebagai berikut:

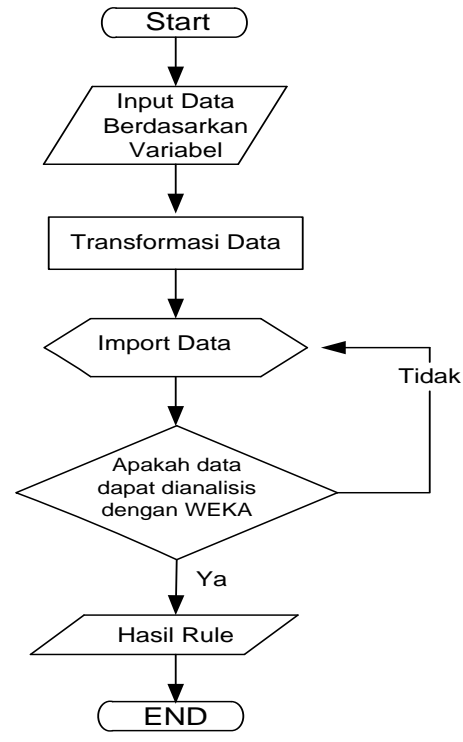

Gambar 2. Flowchart Sistem

\section{Data Pendukung Penelitian}

Data yang digunakan sebagai penelitian adalah sebagai berikut

Tabel 1. Data Penjualan Spare Part

\begin{tabular}{cclc}
\hline No & $\begin{array}{c}\text { Jenis } \\
\text { Kendaraan }\end{array}$ & $\begin{array}{c}\text { Jenis } \\
\text { Spare Part }\end{array}$ & $\begin{array}{c}\text { Merk } \\
\text { Kendaraan }\end{array}$ \\
\hline 1 & Avanza & $\begin{array}{l}\text { Filter Oil } \\
\text { Toyota }\end{array}$ & Toyota \\
\hline 2 & Vios & $\begin{array}{l}\text { Filter Bahan } \\
\text { Bakar Toyota }\end{array}$ & Toyota \\
\hline 3 & Avanza & $\begin{array}{l}\text { Filter } \\
\text { UdaraToyota }\end{array}$ & Toyota \\
\hline 4 & Vios & $\begin{array}{l}\text { Filter } \\
\text { UdaraToyota }\end{array}$ & Toyota \\
\hline 5 & Brio & $\begin{array}{l}\text { Filter Oil } \\
\text { Honda }\end{array}$ & Honda \\
\hline
\end{tabular}

\begin{tabular}{|c|c|c|c|}
\hline 6 & Terios & $\begin{array}{l}\text { Filter Udara } \\
\text { Daihatsu }\end{array}$ & Daihatsu \\
\hline 7 & Ayla & $\begin{array}{l}\text { Filter Oil } \\
\text { Daihatsu }\end{array}$ & Daihatsu \\
\hline 8 & Avanza & Filter Oil Toyota & Toyota \\
\hline 9 & Ertiga & $\begin{array}{l}\text { Filter } \\
\text { UdaraSuzuki }\end{array}$ & Suzuki \\
\hline 10 & Ertiga & $\begin{array}{l}\text { Filter Bahan } \\
\text { BakarSuzuki }\end{array}$ & Suzuki \\
\hline 11 & Brio & $\begin{array}{l}\text { Filter Kabin Non } \\
\text { KarbolHonda }\end{array}$ & Honda \\
\hline 12 & Vios & Filter Oil Toyota & Toyota \\
\hline 13 & Avanza & $\begin{array}{l}\text { Kampas Rem } \\
\text { CakramToyota }\end{array}$ & Toyota \\
\hline 14 & Brio & Filter Oil Honda & Honda \\
\hline 15 & Ayla & $\begin{array}{l}\text { Filter Oil } \\
\text { Daihatsu }\end{array}$ & Daihatsu \\
\hline 16 & Vios & $\begin{array}{l}\text { Filter Bahan } \\
\text { BakarToyota }\end{array}$ & Toyota \\
\hline 17 & Vios & Filter Oil Toyota & Toyota \\
\hline 18 & Ayla & $\begin{array}{l}\text { Filter Oil } \\
\text { Daihatsu }\end{array}$ & Daihatsu \\
\hline 19 & Ertiga & Filter Oil Suzuki & Suzuki \\
\hline 20 & Terios & $\begin{array}{l}\text { Kampas Rem } \\
\text { Cakram Daihatsu }\end{array}$ & Daihatsu \\
\hline
\end{tabular}

Tabel 2. Data Penjualan

\begin{tabular}{|c|c|c|c|}
\hline No & $\begin{array}{c}\text { Jenis } \\
\text { Kendaraan }\end{array}$ & $\begin{array}{c}\text { Jenis } \\
\text { Spare Part }\end{array}$ & $\begin{array}{c}\text { Merk } \\
\text { Kendaraan }\end{array}$ \\
\hline 1 & Avanza & Filter Oil Toyota & Toyota \\
\hline 2 & Vios & $\begin{array}{l}\text { Filter Bahan } \\
\text { Bakar Toyota }\end{array}$ & Toyota \\
\hline 3 & Avanza & $\begin{array}{l}\text { Filter } \\
\text { UdaraToyota }\end{array}$ & Toyota \\
\hline 4 & Vios & $\begin{array}{l}\text { Filter } \\
\text { UdaraToyota }\end{array}$ & Toyota \\
\hline 5 & Brio & Filter Oil Honda & Honda \\
\hline 6 & Terios & $\begin{array}{l}\text { Filter } \\
\text { UdaraDaihatsu }\end{array}$ & Daihatsu \\
\hline 7 & Ayla & $\begin{array}{l}\text { Filter Oil } \\
\text { Daihatsu }\end{array}$ & Daihatsu \\
\hline 8 & Avanza & Filter Oil Toyota & Toyota \\
\hline 9 & Ertiga & $\begin{array}{l}\text { Filter } \\
\text { UdaraSuzuki }\end{array}$ & Suzuki \\
\hline 10 & Ertiga & $\begin{array}{l}\text { Filter Bahan } \\
\text { BakarSuzuki }\end{array}$ & Suzuki \\
\hline 11 & Brio & $\begin{array}{l}\text { Filter Kabin Non } \\
\text { KarbolHonda }\end{array}$ & Honda \\
\hline 12 & Vios & Filter Oil Toyota & Toyota \\
\hline 13 & Avanza & $\begin{array}{l}\text { Kampas Rem } \\
\text { CakramToyota }\end{array}$ & Toyota \\
\hline 14 & Brio & $\begin{array}{l}\text { Filter Oil } \\
\text { Honda }\end{array}$ & Honda \\
\hline 15 & Ayla & $\begin{array}{l}\text { Filter Oil } \\
\text { Daihatsu }\end{array}$ & Daihatsu \\
\hline 16 & Vios & $\begin{array}{l}\text { Filter Bahan } \\
\text { BakarToyota }\end{array}$ & Toyota \\
\hline
\end{tabular}




\begin{tabular}{cclc}
\hline 17 & Vios & $\begin{array}{l}\text { Filter Oil } \\
\text { Toyota }\end{array}$ & Toyota \\
\hline 18 & Ayla & $\begin{array}{l}\text { Filter Oil } \\
\text { Daihatsu }\end{array}$ & Daihatsu \\
\hline 19 & Ertiga & Filter Oil Suzuki & Suzuki \\
\hline 20 & Terios & $\begin{array}{l}\text { Kampas Rem } \\
\text { CakramDaihatsu }\end{array}$ & Daihatsu \\
\hline
\end{tabular}

Tabel 3. Data Jenis Mobil

\begin{tabular}{ccc}
\hline No & Jenis Mobil & Kode \\
\hline 1 & Vios & A1 \\
\hline 2 & Brio & A2 \\
\hline 3 & Ayla & A3 \\
\hline 4 & Avanza & A4 \\
\hline 5 & Ertiga & A5 \\
\hline 6 & Terios & A6 \\
\hline
\end{tabular}

Tabel 4. Data Jenis Spare Part

\begin{tabular}{clc}
\hline No & \multicolumn{1}{c}{ Jenis Spare Part } & Kode \\
\hline 1 & Filter Oli Daihatsu & S1 \\
\hline 2 & Filter Udara Daihatsu & S2 \\
\hline 3 & Kampas Rem Cakram Daihatsu & S3 \\
\hline 4 & Filter Oli Honda & S4 \\
\hline 5 & Filter Kabin Non Karbol & S5 \\
& Honda & \\
\hline 6 & Filter Oli Suzuki & S6 \\
\hline 7 & Filter Udara Suzuki & S7 \\
\hline 8 & Filter Bahan Bakar Suzuki & S8 \\
\hline 9 & Filter Oli Toyota & S9 \\
\hline 10 & Filter Udara Toyota & S10 \\
\hline 11 & Filter Bahan Bakar Toyota & S11 \\
\hline 12 & Kampas Rem Cakram Toyota & S12 \\
\hline
\end{tabular}

Tabel 5. Merk Mobil

\begin{tabular}{ccc}
\hline No & Merk Mobil & Kode \\
\hline 1 & Honda & M1 \\
\hline 2 & Daihatsu & M2 \\
\hline 3 & Suzuki & M3 \\
\hline 4 & Toyota & M4 \\
\hline
\end{tabular}

Tabel 6. Representasi Data Penjualan

\begin{tabular}{|c|c|c|c|c|c|c|c|c|c|c|c|c|c|c|c|c|c|c|c|c|c|}
\hline & \multicolumn{5}{|c|}{ Jenis.lobil } & \multicolumn{12}{|c|}{ Jenis Spare Part } & \multicolumn{4}{|c|}{ Merk Mobil } \\
\hline & \begin{tabular}{|l|l}
$\mathrm{Al}$ & \\
\end{tabular} & & & & & & & & & & & & & & & & & & & & \\
\hline 1 & 0 & 0 & 0 & 1 & & & 0 & 0 & 0 & 0 & 0 & 0 & 0 & 1 & 0 & 0 & 0 & 0 & 0 & 0 & \\
\hline 2 & 1 & 0 & 0 & 0 & 0 & 0 & 0 & 0 & 0 & 0 & 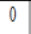 & 0 & 0 & 0 & 0 & 1 & 0 & 0 & 0 & 0 & \\
\hline 3 & 0 & 0 & 0 & 1 & 0 & 0 & $\overline{0}$ & 0 & 0 & 0 & 0 & 0 & 0 & 0 & 1 & 0 & 0 & 0 & 0 & 0 & \\
\hline 4 & 1 & 0 & 0 & 0 & 0 & & 0 & 0 & 0 & 0 & 0 & 0 & 0 & 0 & 1 & 0 & 0 & 0 & 0 & 0 & \\
\hline 5 & 0 & 1 & 0 & 0 & 0 & 0 & 0 & 0 & 1 & 0 & 0 & 0 & 0 & 0 & 0 & 0 & 0 & 1 & 0 & 0 & \\
\hline 0 & 0 & 0 & 0 & 0 & 0 & 0 & 1 & 0 & 0 & 0 & 0 & 0 & 0 & 0 & 0 & 0 & 8 & 0 & 1 & 0 & \\
\hline 7 & 0 & 0 & 1 & 0 & & 1 & 0 & 0 & 0 & 0 & 0 & 0 & 0 & 0 & 0 & 0 & 0 & 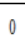 & 1 & \begin{tabular}{l|l} 
\\
\end{tabular} & 0 \\
\hline 8 & 0 & 0 & 0 & 1 & 0 & 0 & 0 & 0 & 0 & 0 & 0 & 0 & 0 & 1 & 0 & 0 & 0 & 0 & 0 & 0 & \\
\hline 9 & 0 & 0 & 0 & 0 & & , & 0 & 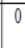 & 0 & 0 & 0 & 1 & 0 & 0 & 0 & 0 & 0 & 0 & 0 & 1 & 0 \\
\hline & & 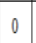 & 0 & 0 & & & & & 0 & & 0 & 0 & 1 & 0 & 0 & 0 & 0 & & 0 & 1 & \\
\hline
\end{tabular}

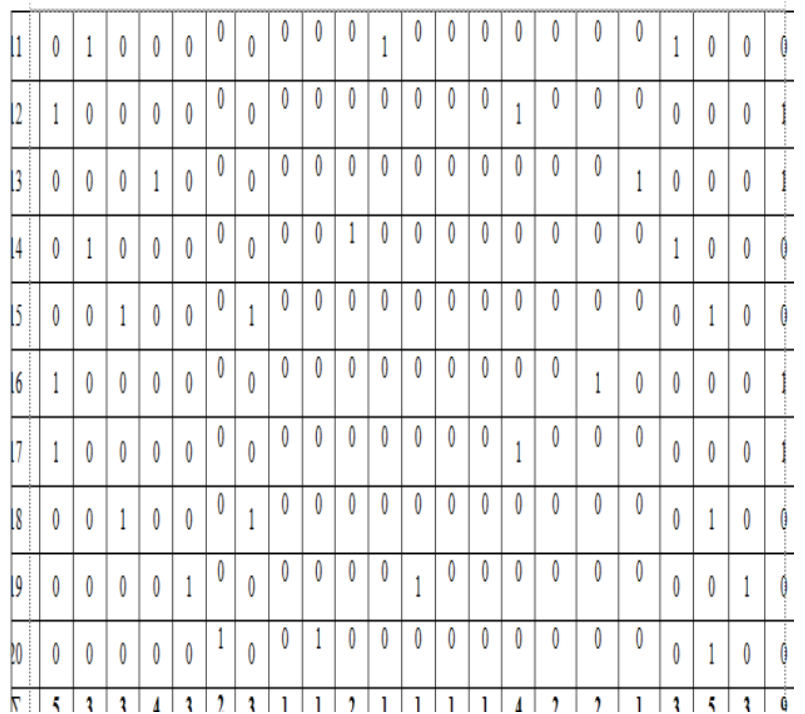

Tabel 7. Calon 2 Item Set Perhitungan Iterasi I

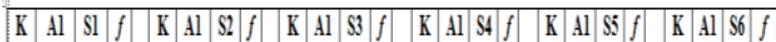

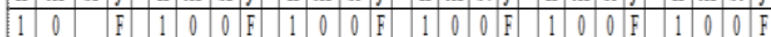

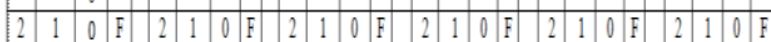

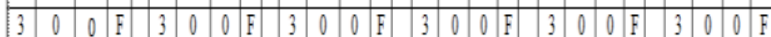

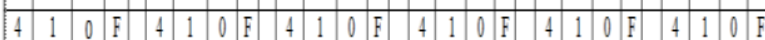

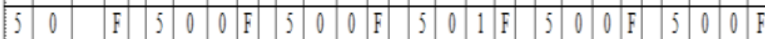

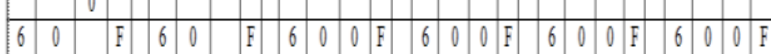

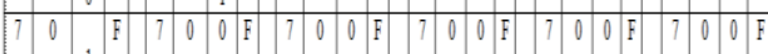

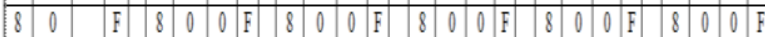

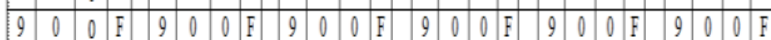

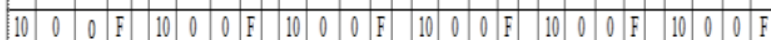

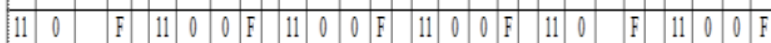
\begin{tabular}{|l|l|l|l|l|l|l|l|l|lllllllllllllll}
\hline 12 & 1 & & F & 12 & 1 & 0 & $F$ & 12 & 1 & 0 & $F$ & 12 & 1 & 0 & $F$ & 12 & 1 & 0 & $F$ & 12 & 1 & 0 & $F$ \\
\hline
\end{tabular}

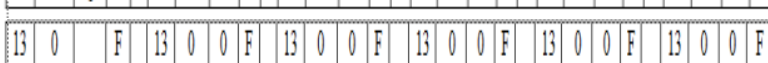

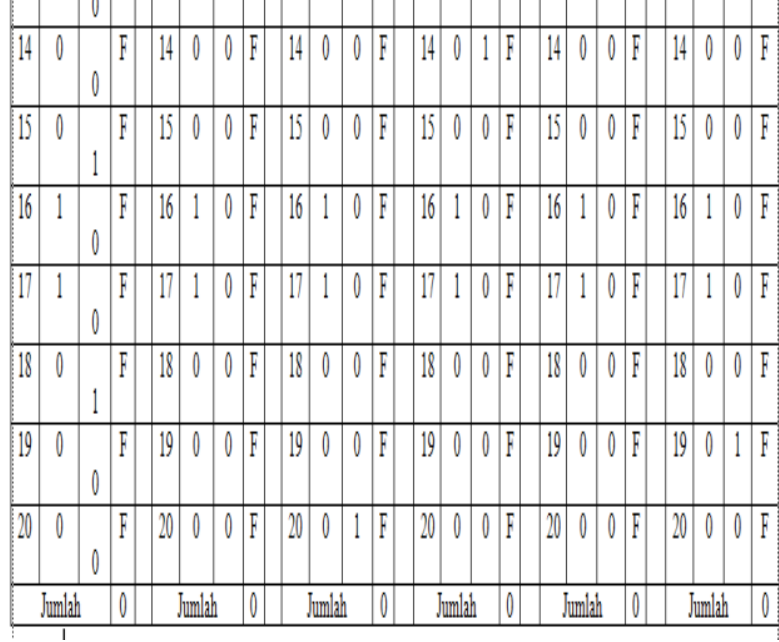


Tabel 8. Calon 3 Itemset Perhitungan Iterasi 2

\begin{tabular}{ccccc}
\hline K & A3 & M2 & S1 & $\boldsymbol{f}$ \\
\hline 1 & 0 & 0 & 0 & $\mathrm{~F}$ \\
\hline 2 & 0 & 0 & 0 & $\mathrm{~F}$ \\
\hline 3 & 0 & 0 & 0 & $\mathrm{~F}$ \\
\hline 4 & 0 & 0 & 0 & $\mathrm{~F}$ \\
\hline 5 & 0 & 0 & 0 & $\mathrm{~F}$ \\
\hline 6 & 1 & 1 & 0 & $\mathrm{~F}$ \\
\hline 7 & 1 & 1 & 1 & $\mathrm{~T}$ \\
\hline 8 & 0 & 0 & 0 & $\mathrm{~F}$ \\
\hline 9 & 0 & 0 & 0 & $\mathrm{~F}$ \\
\hline 10 & 0 & 0 & 0 & $\mathrm{~F}$ \\
\hline 11 & 0 & 0 & 0 & $\mathrm{~F}$ \\
\hline 12 & 0 & 0 & 0 & $\mathrm{~F}$ \\
\hline 13 & 0 & 0 & 0 & $\mathrm{~F}$ \\
\hline 14 & 0 & 0 & 0 & $\mathrm{~F}$ \\
\hline 15 & 1 & 1 & 1 & $\mathrm{~T}$ \\
\hline 16 & 0 & 0 & 0 & $\mathrm{~F}$ \\
\hline 17 & 0 & 0 & 0 & $\mathrm{~F}$ \\
\hline 18 & 1 & 1 & 1 & $\mathrm{~T}$ \\
\hline 19 & 0 & 0 & 0 & $\mathrm{~F}$ \\
\hline 20 & 1 & 1 & 0 & $\mathrm{~F}$ \\
\hline & & Jumlah & & 3 \\
\hline & & & &
\end{tabular}

Untuk mengetahui hubungan atau korelasi antar item kekuatan hubungan ditentukan oleh 2 faktor yang support dan confidence, yang diperoleh dengan rumus sebagai berikut:

Support $=$ Nilai pendukung

Support $=\frac{\sum \text { Item yang digunakan }}{\sum \text { Jumlah seluruh transaksi }} \times 100 \%$

Confidence $=$ Nilai Kepastian

Confidence $=$

SItem yang digunakan sekaligus

$\frac{\sum \text { Jumlah seluruh transaksi pada bagian antecedent }}{x} 100 \%$

Rule untuk 1itemset terdiri atas 1 rule yang diimplementasikan pada tabel berikut:

Tabel 9. Aturan Asosiasi 3Item Set

\begin{tabular}{ccc}
\hline $\begin{array}{c}\text { If Antecendent } \\
\text { then Consequent }\end{array}$ & Support & Confidence \\
\hline If $\mathrm{A} 3 \quad \mathrm{M} 2 \rightarrow \mathrm{S} 1$ & $\begin{array}{c}3 / 20 \times 100 \% \\
=15 \%\end{array}$ & $\begin{array}{c}3 / 3 \times 100 \% \\
=100 \%\end{array}$ \\
\hline
\end{tabular}

Tabel 10. Aturan Asosiasi 3Item Set

\begin{tabular}{cccc}
\hline $\begin{array}{c}\text { If Antecendent } \\
\text { then Consequent }\end{array}$ & Support & Confidence & S*C \\
\hline If $\quad \mathrm{A} 3 \quad \mathrm{M} 2 \rightarrow \mathrm{S} 1$ & $15 \%$ & $100 \%$ & $15 \%$ \\
\hline
\end{tabular}

Tabel 11. Best Rule

\begin{tabular}{lcccc}
\hline $\begin{array}{c}\text { If Antecendent } \\
\text { then Consequent }\end{array}$ & Support & Confidence & $\mathrm{S} * \mathrm{C}$ \\
\hline If $\quad \mathrm{A} 3 \quad \mathrm{M} 2 \rightarrow \mathrm{S} 1$ & $15 \%$ & $100 \%$ & $15 \%$ \\
\hline
\end{tabular}

If $\mathrm{A} 3$ and $\mathrm{M} 2$ then $\mathrm{S} 1$ dengan nilai support $=15 \%$ dan Confidence $=100 \%$ dan nilai $\mathrm{S} * \mathrm{C}=15 \%$. Jika A3 ( Jenis mobil Ayla) dan dengan merk mobil adalah M2 (Daihatsu) maka sparepart yang digunakan oleh mobil tersebut adalah S1 (Filter oli Daihatsu)dengan nilai pendukung sebesar $15 \%$ dan nilai kepastian sebesar $100 \%$.

\section{Pembahasan Dan IMPLEMEnTaSi}

\section{A. Pembahasan}

Langkah-langkah yang dilakukan untuk perhitungan data pada penjualan sparepart mobil menggunakan metode Apriori, agar dapat dihasilkan sebuah pengetahuan baru mengetahui hubungan antara jenis mobil, merek mobil dan jenis spare part mobil yang dijual pada penelitian ini.

1. Tampilan Menu Awal pada WEKA

Tampilan utama yang akan dilihat oleh user pada saat pertama kali membuka perangkat lunak WEKA. Berikut proses pre-processing yang dilakukan pada tool WEKA. Pertama yang harus dilakukan adalah membuka WEKA dan klik Explorer.

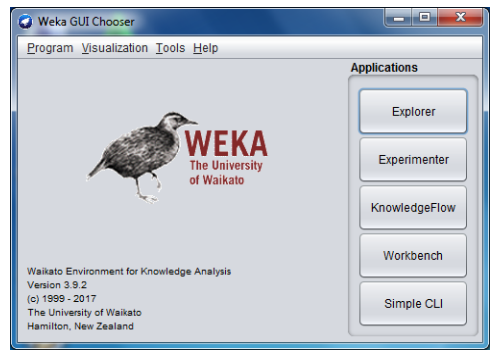

Gambar 3. Tampilan Utama WEKA

a. Explorer

Digunakan untuk mencari algoritma yang paling cocok untuk data. Semua data diload ke memori sehingga dapat cepat diproses, tapi hanya dapat digunakan untuk data dengan jumlah terbatas.

b. Eksperimenter

Digunakan untuk mencari parameter yang cocok. Mirip dengan explorer tetapi prosesnya dapat diautomatisasi. Eksperimen ukuran besar (multi machine dengan RMI) dapat dilakukan dengan interface ini.

c. KnowledgeFlow

Digunakan untuk memproses data stream. Konfigurasi proses dapat diatur dengan mudah dan dapat menangani data berukuran besar. Mendukung incremental learning.

d. Simple CLI

(Command Line Interface) menggunakan command line untuk interface.

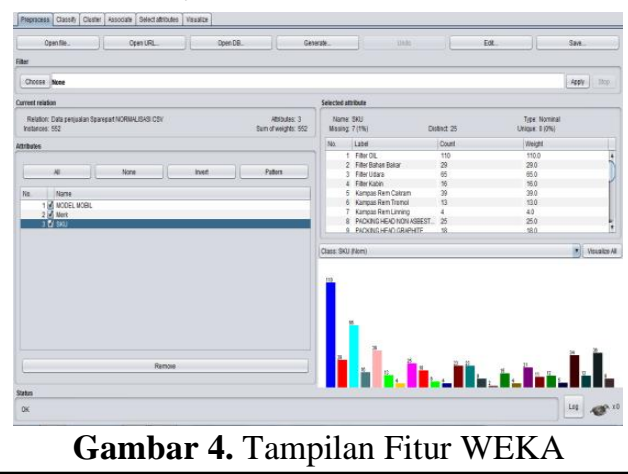


Selanjutnya klik associate lalu klik pada apriori dan tentukan Support dan Confidence lalu Ok. Selanjutnya klik START maka hasil rule akan terbentuk.

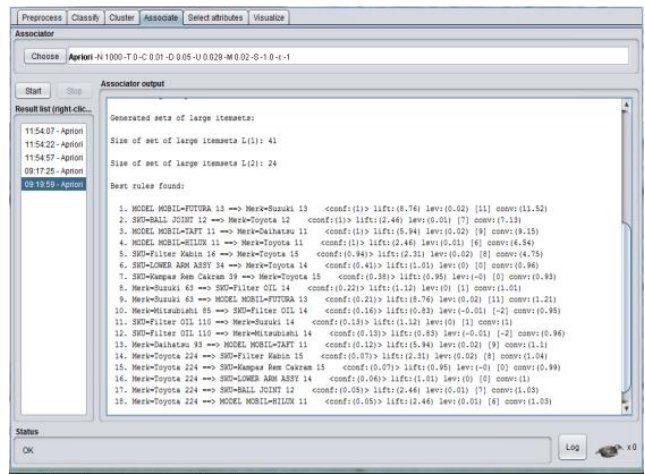

Gambar 5. Tampilan Menu Apriori

\section{FormHome}

Form ini muncul pada saaat membuka halaman web. Form ini mempunyai 4 menu yang biasa diakses yaitu Home, Asosiasi, Tampil data, Input Data, Input Rule, Tampil Rule, Tentang, Logout. Pada form ini hanya merupakan halaman utama dan tampilannya secara default akan seperti rancangan dibawah ini.

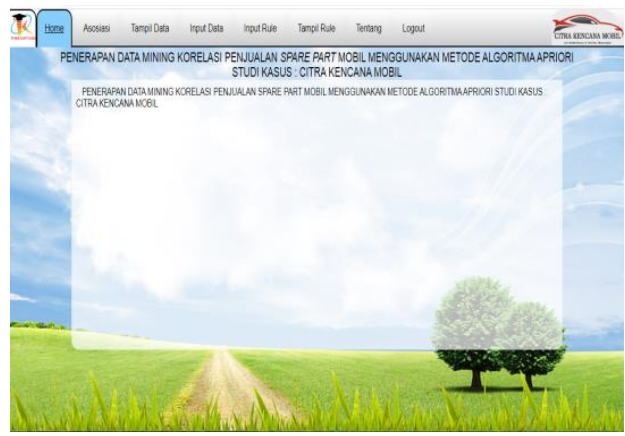

Gambar 6. FormHome

\section{Form Tampil Data}

Form Tampil Data dapat diakses dengan klik menu data. Pada form ini, akan menampilkan keseluruhan data penjualan sparepart yang sebelumnya akan diolah menjadi rule di WEKA.

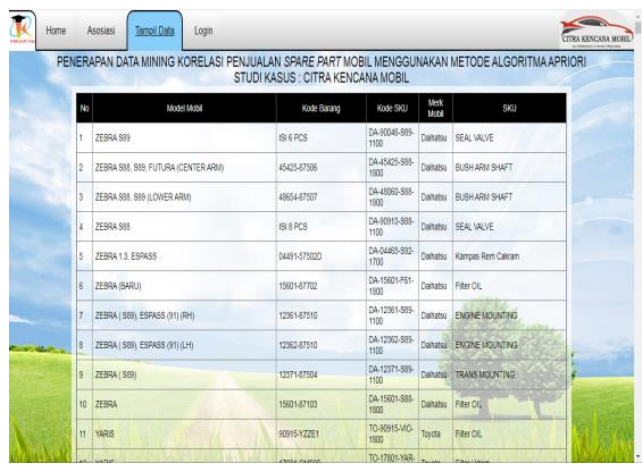

Gambar 7. FormTampil Data

\section{FormLogin}

FormLogin muncul ketika user klik menu yang membutuhkan akses admin untuk menampilkannya. Form ini merupakan proses validasi untuk menuju form admin untuk melakukan proses input ataupun hapus rule.

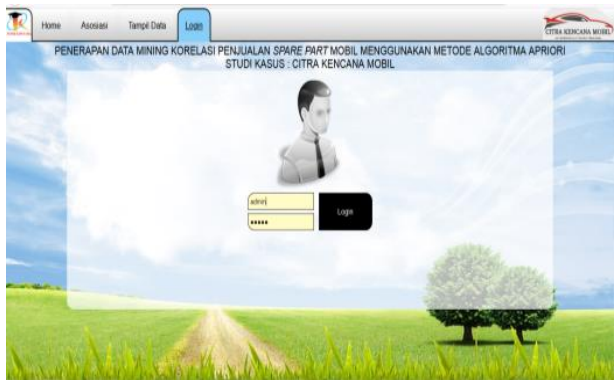

Gambar 8. FormLogin

5. FormAsosiasi

Form ini merupakan form inti dari sistem, user maupun admin dapat mengakses form ini. Untuk menggunakannya, user maupun admin harus memasukkan minimal 2 dan maksimal 3variabel yang sudah ada dalam combobox lalu klik proses, maka hasil rule akan tampil.

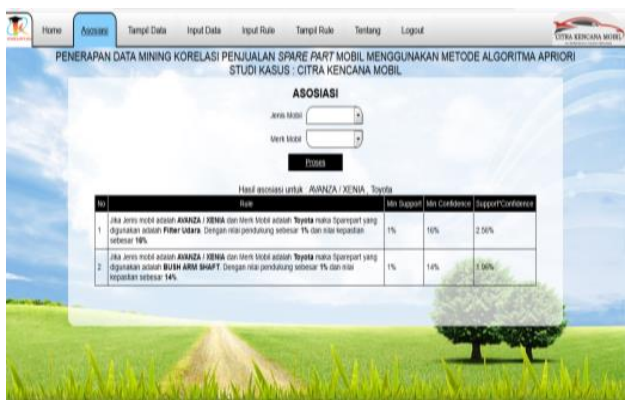

Gambar 9. FormApriori

\section{Form Admin}

Form ini merupakan halaman admin yang brguna untuk mengelola isi di dalam program seperti input data, inputrule, ubah password, ubah logo, ubah tentang dan export data serta export rule.

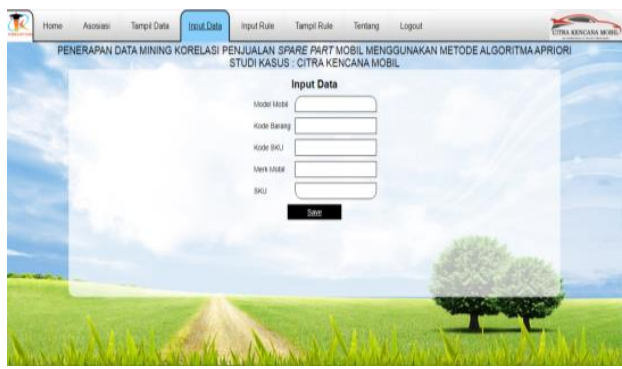

Gambar 10. FormAdmin

\section{FormInput Rule}

Form ini merupakan untuk menginput dan menampilkan rule. Rule yang sudah dihasilkan di WEKA diinput ke sistem melalui formrule dan juga dapat edit dan menghapus rule.

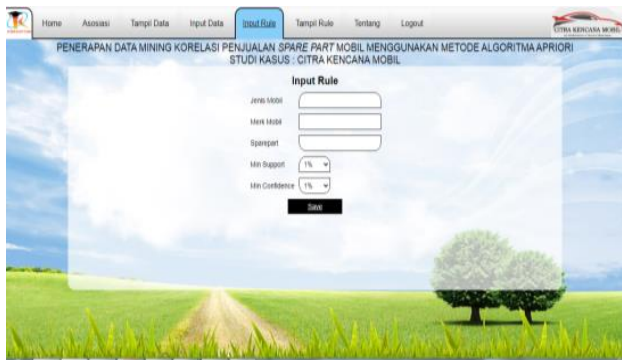

Gambar 11. FormInput Rule 


\section{B. Implementasi}

Tahap implementasi perangkat lunak merupakan kelanjutan dari tahap perancangan, sehingga implementasi ini harus didasarkan pada perancangan yang telah dilaksanakan sebelumnya dan pengujian dilakukan untuk melihat apakah setiap proses yang berjalan dengan baik dan output yang dihasilkan sudah sesuai dengan yang diharapkan.

Rule yang sudah terbentuk menggunakan pemrograman PHP dan Database menggunakan MySQL.

1. Uji Coba Sistem dan Program Penemuan Rule

Dari pengelolahan data penjualan spare part mobil pada aplikasi WEKA maka didapat pembentukan rulerule terbaik yang nantinya dapat digunakan untuk sistem Korelasi Penjualan Sparepart Mobil Menggunakan Metode Apriori. Uji coba dilakukan dengan rentang support 0.01 hingga support 1.0 jadi terdapat 54 rule.

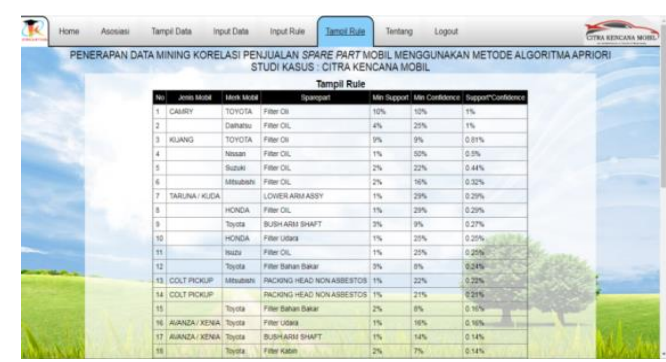

Gambar 11. Hasil Data Uji Program

\section{KESIMPULAN DAN SARAN}

Berdasarkan hasil analisis permasalahan yang di dapat, maka di ambil kesimpulan yaitu dengan dibangunnya sistem pendukung keputusan untuk menentukan prioritas perbaikan sarana dan prasarana sekolah dasar dengan metode MOORA akan lebih efektif dan efisiensi. Perbaikan sarana dan prasarana sekolah dasar yang dihasilkan dapat diterima oleh semua pihak dan tepat sasaran serta sistem pendukung keputusan ini akan meminimalisi kesalahan kesalahan dalam proses pemasukan data.

\section{B. Kesimpulan}

Berdasarkan hasil dari penelitian dan pembahasan yang telah dilakukan dapat diambil kesimpulan yaitu sebagai berikut:

1. Dari pengujian data yang telah dilakukan, penerapanaturan asosasi data mining dengan menggunakan algoritma apriori dapat digunakan untuk mencari korelasi penjualan sparepart mobil menggunakan algoritma apriori (studi kasus: CV. Citra Kencana Mobil).

2. Dengan menentukan rule minimal 3 item set untuk penerapan algoritma k-apriori pada korelasi penjualan sparepart mobil ditemukan maksimum support adalah sebesar $9 \%$ yaitu sebanyak 81 rule dengan support dan confidence yang beragam.

3. Dari hasil pengujian penjualan sparepart mobil dengan jumlah data 589 data, ditemukan 81 rule yang terbentuk dan diperoleh Best Rule tertinggi dan nilai minimum support $1 \%$ dan nilai confidence $11 \%$ Jika jenis Mobil adalah Avanza/Xenia dan Merk adalah Toyota maka sparepart yang digunakan adalah Filter Udara. Dengan sparepart pendukung di dalam database sebesar 1\% dan sparepart kepastian sebesar $11 \%$.

\section{B. Saran}

Mengingat keterbatasan yang dimiliki oleh penulis, baik pengetahuan, waktu maupun pemikiran, maka penulis dapat memberikan saran yang dapat dijadikan sebagai acuan dari hasil penelitian ini dimasa yang akan datang yaitu sebagai beriku:

1. Untuk penelitian berikutnya agar dapat menggunakan berbagai metode lainnya dalam melakukan data mining pada data penjualan sparepart mobil.

2. Untuk penelitian selanjutnya agar dapat menambah lebih banyak lagi data penjualan spare part mobil agar didapat hasil yang lebih baik lagi.

\section{DAFTAR PUSTAKA}

[1] Betha Sidik, Ir., (2004), Pemrograman Web dengan PHP, Informatika, Bandung.

[2] Khairul, Ummi. (2015), ANALISA DATA MINING DALAM PENJUALAN SPAREPART MOBIL DENGAN MENGGUNAKAN METODE ALGORITMA APRIORI (STUDI KASUS : DI PT. IDK 1 MEDAN). Universitas Potensi Utama.

[3] Indrajit, R. E., \& Djokopranoto, R. (2003). Manajemen Persediaan, Barang Umum dan Suku Cadang Untuk Pemeliharaan dan Operasi. Jakarta: Grasindo.

[4] Larose, Daniel T. 2005. Discovering Knowledge In Data: An Introduction to Data mining. New Jersey: JohnWilley\& Sons. Inc.

[5] Latief Zulbiadi. 2009. 50 Bisnis Jasa Menguntungkan. Jakrata: Trans media Pustaka.

[6] Listriani, D., Setyaningrum, A. H., \& Eka, F. (2018). PENERAPAN METODE ASOSIASI MENGGUNAKAN ALGORITMA APRIORI PADA APLIKASI ANALISA POLA BELANJA KONSUMEN (Studi Kasus Toko Buku Gramedia Bintaro). JURNAL TEKNIK INFORMATIKA. https://doi.org/10.15408/jti.v9i2.5602.

[7] Grata, Fendy, and Darsono Nababan. "Analisis Terhadap Data Penjualan Produk Kebutuhan Rumah Tangga Menggunakan Algoritma Apriori."

[8] Santoso, Singgih. 2007. Statistik Deskriptif: Konsep dan Aplikasi dengan Microsoft Exel dan SPSS. Yogyakarta: ANDI.

[9] Yuli Mardi. 20015. Principles of Data Mining. London sprin. 